\title{
Motivating adolescents to reduce risk for chronic disease
}

\author{
Christine L. Williams \\ M.D.
}

\author{
ERNST L.WYNDER \\ M.D.
}

\section{Department of Child Health, American Health Foundation, New York, U.S.A.}

\begin{abstract}
Summary
Motivating children to reduce risk for future disease can only be effective within a framework of personal involvement and peer interaction. The 'Know Your Body' programme of disease prevention is attempting to achieve this goal by means of medical screening for risk factors, giving students their own results in a 'Health Passport', and following up with educational activities integrated into existing school curricula. Didactic teaching alone has been unsuccessful because children cannot relate information about diseases in adult life to themselves. Screening for risk factors provides the 'reality factor' which makes health education pertinent and personal, since approximately half of all students screened will already have one or more risk factors for heart disease, cancer or stroke. This high prevalence of risk factors among our children suggests that chronic-disease prevention must assume a critically important position within the health and science curricula of every school. It is as important to teach our children healthy ways of living as it is to teach reading, writing, and arithmetic.
\end{abstract}

THE majority of intervention trials designed to reduce coronary risk factors and subsequent morbidity and mortality from atherosclerotic heart disease have focused on middle-aged men. In terms of the natural history of the disease itself, there is much less that can be done to alter the course of this slowly progressive disease at such a late stage in life since evidence is clear that its roots begin early in childhood.

The size of the problem is enormous. Heart disease, cancer and stroke (HCS) are together responsible for over two-thirds of adult deaths in countries such as the United States and Great Britain. Research has failed to show that the responsible factors are either single or communicable. Rather, evidence has grown that their causes are multifactorial in nature and are predominantly environmental and self-inflicted. These risk factors are largely related to our life styles, particularly what we eat, drink and smoke and how we exercise. Their sum effects operate within a framework of genetic susceptibility which together determine whether we will or will not ultimately develop that disease. Prospective studies such as the Framingham Study have provided us with the means of calculating actual risk ratios for individualso based on the number and magnitude of risk factor present.

It is clear from post-mortem studies of childrenis and adolescents dying accidentally and in wartime that atherosclerosis begins early in life. Almost al[ children demonstrate fatty streaks in their aortasi by the age of 3 years; and under the influence of Western life styles, they progress through a pre옥 dictable series of disease stages. Among U.S. soldiers killed in the Korean War, $77 \%$ had evidence of coronary atherosclerosis (Enos, Holmes and Beyer $\frac{}{7}$ 1953). During the Vietnamese conflict, $45 \%$ of U.S. casualties had some pathological evidence coronary atherosclerosis at a mean age of 22 ye (McNamara et al., 1971). Secondly, recent studes have shown that HCS risk factors are highly prepa lent among children from an early age, even usings adult cut-off levels for cholesterol and blood pressure which are clearly too high for children. The mosp common risk factors demonstrable among children? are raised blood cholesterol $(18 \%$ are over 4.65 $\mathrm{mmol} / \mathrm{l})$, obesity $(16 \%$ are at least one-fifth $>$ the ideal weight for height, age and sex), and cigarette smoking $(25 \%$ of high-school students smoke. regularly) (Williams, Arnold and Wynder, 1977\% Williams and Wynder, 1976; Kandel, Single and. Kessler, 1976). In addition, it is probable that the top $5 \%$ of children, based on blood pressure deter minations, are at risk for hypertension and should be followed closely with special preventive measures (weight control, salt reduction) (Task Force on Blood Pressure Control in Children, 1977).

Various studies suggest that atherosclerosis is: probably reversible in man until the end of the second decade of life, so that any hope of com: pletely preventing this disease process must begin in childhood.

Unfortunately for many paediatricians, the pre을 vention of heart disease, cancer and stroke is muclo more difficult than a simple innoculation against rubella. Rather, we are dealing with a complex web? of factors related to our every-day habits and per $=0$ sonal life styles. Changing them in a healthiep direction requires a knowledge of how to motivate 
human behaviour. Such skills have not only rarely been taught in medical school, but also are apt to consume a larger portion of a physician's time than classical prescription remedies.

It is for these reasons that schools are considered to be a more appropriate site for a campaign of preventive medicine aimed at behaviour modification toward healthier life styles. Prevention must involve all children since cardiovascular diseases eventually affect the majority of them as adults. Schools already have resources for health education and can provide opportunities for children to encourage each other in healthier ways of living.

The decision to incorporate a primary prevention programme aimed at reducing risk for heart disease, cancer, and stroke within the school system comes first. Next and most important is motivating students (1) to participate personally in the programme, and (2) to modify their life styles in the appropriate direction if they are at increased risk (i.e. to respond to the risk factor intervention activities).

The following description of a prototype programme incorporating these concepts within several schools in the New York City area is provided to suggest means of achieving the above goals.

\section{Know your body programme (KYB)}

The programme was developed around a belief that certain essential steps within a school setting are necessary to motivate adolescents to reduce their own risk for disease.

(1) They must be medically screened to become aware of their own risk status and to provide them with a personal frame of reference on which to make future health decisions based on subsequent information.

(2) They must receive their own results. A student looking at a cholesterol level of $6.1 \mathrm{mmol} / 1$ in her own 'Health Passport' will be more impressed than being informed by a parent or physician that her cholesterol level is 'on the high side'.

(3) They must receive post-screening educational materials on risk factor significance and reduction in order to know what to do.

(4) They must be channelled into active intervention programmes within a peer setting so that healthy behaviour becomes the norm rather than the exception. Details of this programme have been described in a report (Williams, 1977).

Over 2700 students were screened during the initial year of the KYB programme in New York. Of these students, $36 \%$ were found to have one or more risk factors, the most common were raised cholesterol level, overweight, cigarette smoking or below-average response to exercise.

The first step in motivating behaviour change to reduce risk for disease is to give the students their own results. An individual must first know what needs to be changed and then how to do it. Unfortunately, health education in the past has neglected this personal factor. In general terms schools have advocated 'eat right', 'don't smoke', 'don't drink', etc., but to the students this means someone else, not them, not now. In contrast, the exercise of giving students their screening results clearly says: 'you ... this passport contains your own results, and what you do about it is up to you personally and your family'.

One treads a fine line between creating a concern in the individual enough to motivate behaviour change to reduce risk (i.e. to reduce weight if obese, to reduce fats and cholesterol if hypercholesterolaemic, etc.) and at the same time to avoid anxiety. Parents are sometimes concerned about the child getting his own results in school; however, in the author's experience, the children are much more objective about this than their elders. Unfortunately society has classically felt that medical news (particularly bad news) should be shielded from the patient. In the case of chronic disease risk factors, such shielding is counter-productive. Children must want to eat a more prudent diet, exercise more, control their weight, and abstain from smoking. Being aware of their own risk, and responsibility for their own bodies are the first steps in creating this desire.

The screening programme is all done on a completely voluntary basis by teachers and administrators. The ultimate goal of motivating adolescents to reduce risk factors has begun and the degree to which we are successful cannot be known for several years.

Perhaps the behavioural changes we seek should be programmed much earlier in life. While adolescents are taking more responsibility for their own care, many have already adopted their parents' eating, exercising, and smoking habits. For this reason, the KYB programme will shortly begin a pilot study in order to intervene in cases of increased risk status at a much earlier age.

In summary, the authors believe that what has been learned to date is the following:

(1) It is indeed feasible to undertake a comprehensive chronic disease prevention programme involving medical screening for risk factors and health education within the schools with support from parents, teachers, and students at an acceptable level of classroom time commitment.

(2) That this type of programme has a wide range of acceptance and appeal from inner city, depressed areas to upper class, professional populations. 


\section{Acknowledgment}

This work has been supported by National Cancer Institute Contract No. 17867.

\section{References}

Enos, W., Holmes, R. \& Beyer, J. (1953) Coronary disease among U.S. soldiers killed in Korea. Journal of the American Medical Association, 152, 1090.

Kandel, K., Single, E. \& Kessler, R.C. (1976) The epidemiology of drug use among New York State high school students: distribution, trends and change in rates of use. American Journal of Public Health, 66, 43.

McNamara, J.J., Molot, M.A., STremple, J.F. \& Cutting,
R.T. (1971) Coronary artery disease in combat casualties in Vietnam. Journal of the American Medical Association? 216, 1185.

TAsk Force on Blood Pressure Control in Childre (1977) National Heart, Lung and Blood Institute an $\$$ National High Blood Pressure Education Programo Pediatrics, 59, 797.

Williams, C.L., ARNold, C.A. \& Wynder, E.L. (1977할 Primary prevention of chronic disease beginning in child hood. The "Know Your Body" program: design of studyळ Preventive Medicine, 6 (in press).

WILliams, C.L. \& WYNDER, E.L. (1976) Blind spot in pre ventive medicine; a commentary. Journal of the America $\vec{b}$ Medical Association, 236, 2196. 